\title{
Covalent Attachment of Carbohydrate Derivatives to an Evanescent Wave Fiber Bragg Grating Biosensor
}

\author{
Christopher J. Stanford, ${ }^{1}$ Geunmin Ryu, ${ }^{1}$ Mario Dagenais, ${ }^{1}$ Matthew T. Hurley, ${ }^{2}$ \\ Karen J. Gaskell, ${ }^{2}$ and Philip DeShong ${ }^{2}$ \\ ${ }^{1}$ Department of Electrical and Computer Engineering, University of Maryland, College Park, MD 20742, USA \\ ${ }^{2}$ Department of Chemistry and Biochemistry, University of Maryland, College Park, MD 20742, USA
}

Correspondence should be addressed to Mario Dagenais, dage@ece.umd.edu

Received 5 March 2009; Revised 2 July 2009; Accepted 11 August 2009

Recommended by Christos Riziotis

A carbohydrate-based biosensor was prepared by functionalization of the surface of an etched fiber Bragg grating with a glucopyranosyl-siloxane conjugate. Functionalization of the surface with the conjugate resulted in a Bragg grating shift of 24 pm. This shift in the refractive index is consistent with a theoretical shift calculated assuming monolayer coverage of the glucose conjugate on the sensor. The resulting functionalized fiber was shown to interact selectively with concanavalin A (Con A), a glucose binding protein (lectin). Exposure of the glucose-functionalized fiber to peanut agglutinin, a galactosebinding lectin, did not result in a change of the refractive index corresponding to a binding event.

Copyright (C) 2009 Christopher J. Stanford et al. This is an open access article distributed under the Creative Commons Attribution License, which permits unrestricted use, distribution, and reproduction in any medium, provided the original work is properly cited.

\section{Introduction}

Biosensors play an increasingly important role in the detection of substances in the environment: they are employed for the detection of viral or bacterial pathogens in the food supply, to biodefense threats such as anthrax, to glucose monitoring of diabetes. [1-7] A variety of biomolecules have previously been attached to silica and related surfaces to provide recognition regimes for biochemical substances, including single strand DNA, antibodies, enzymes, proteins, and cells. In addition to single substrate biosensors, the ability to multiplex biosensors into arrays has provided greater sensitivity to the detection capabilities and array technology has greatly enhanced the study of genomic science, for example.

The functionalization of silica with carbohydrate derivatives, on the other hand, has received skant attention even though carbohydrate-protein interactions at cell surfaces are known to play critical roles in reproduction, infectivity, and tumor metastasis [8-12]. In addition, since many carbohydrate binding events are multidentate in nature and require the simultaneous binding of multiple sugars on the surface of cells, biosensors with a high surface coverage of carbohydrate should provide an ideal platform for the study of carbohydrate-protein interactions. Recently carbohydratebased biosensors that exploit this multidentate binding have been reported by Izumi and Uzawa [13] and Jelinek and Kolusheva [14]. In addition, Taitt et al. have recently reported a carbohydrate-based array biosensor for use in the detection of toxins in food and clinical fluids [15].

In this paper, we describe the preparation of a carbohydrate-functionalized, etched evanescent wave fiber Bragg grating biosensor and study its binding to the glucosebinding protein (lectin) concanavalin A (Con A). These experiments are the initial step toward the development of carbohydrate-functionalized fibers as biosensors for the detection of carbohydrate binding proteins (lectins). Our immediate goal is to produce a biosensor based on glycorecognition which should provide distinct advantages over DNA and antibody/antigen sensors. For example, since the binding is analogous to cell-cell recognition, the sensor should occur without the requirement for cell lysis (or other cell preparation methodology). In addition, since cell-cell recognition is known to be fast (seconds) on the biological 


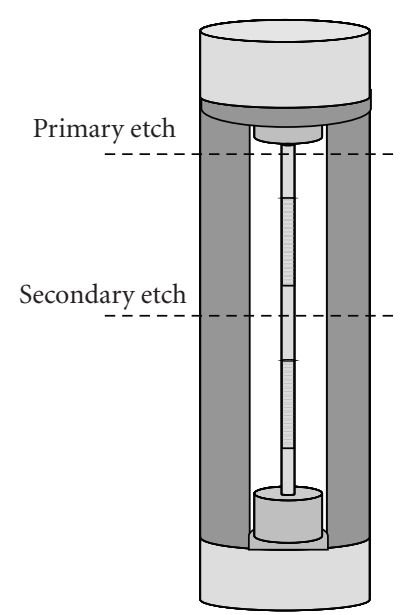

(a)

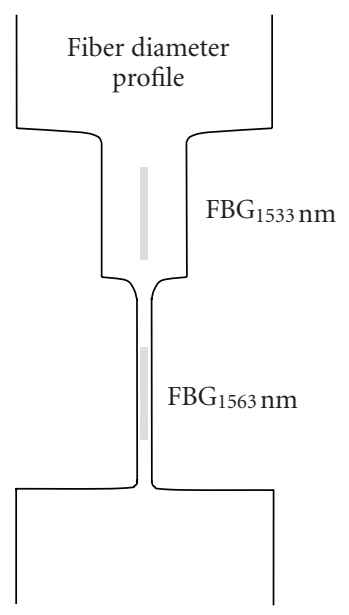

(b)
FIGURE 1: (a) Diagram of the JDSU fiber housing and positions of the etchant during primary and secondary etches; (b) fiber diameter profile after secondary etch.

timescale, one can anticipate that the sensor will function in the same time regime to provide virtually real time analysis of the binding event. Cell-cell recognition is very fast compared to DNA hybridization (hours) and thus the glycosensor may have much faster response times than other types of biological interactions. Once we have demonstrated that a single fiber with one carbohydrate can function as a sensor, then the multiplexing of fibers will be investigated.

\section{Experimental Section}

2.1. Fiber Optic System. Our fiber optics sensor [16, 17] uses a commercially available (JDSU) single mode photosensitive fiber in which two fiber Bragg gratings (FBGs), with a Bragg wavelength of 1533 and $1563.8 \mathrm{~nm}$, are inscribed in the fiber core. The gratings are about $5 \mathrm{~mm}$ long and they have a peak reflectivity of about $30 \mathrm{~dB}$ and extremely well-suppressed sidelobes. Measurements from designing a temperature-compensated mount reveal that the JDSU fiber has a thermo-optic coefficient of $9.8 \times 10^{-6} /{ }^{\circ} \mathrm{C}$. The JDSU fiber is a germanosilicate fiber that has been hydrogen loaded to enhance the photosensitivity. Both FBGs are packaged in a single temperature-compensated mount. For an unetched fiber, the temperature sensitivity was measured to be $-0.1 \mathrm{pm} /{ }^{\circ} \mathrm{C}$ for temperatures within $10^{\circ} \mathrm{C}$ from room temperature. The FBG sensors were chemically etched in a two-step process. Fiber etching was conducted in $7: 1$ buffered oxide etch with surfactant from J. T. Baker. Based on the MSDS data sheet, the solution is made up of $0.5 \%-10 \%$ hydrogen fluoride, $40 \%-70 \%$ water, 30\%-50\% ammonium fluoride, and $0.5 \%-10 \%$ surfactant. The low concentration of hydrogen fluoride and the addition of surfactant reduce the silica etch rate and enhance the surface smoothness, as compared to etching processes utilizing higher hydrogen fluoride concentrations. The etch rate is very stable for a fixed temperature and at $23^{\circ} \mathrm{C}$ the fiber etches at a rate of

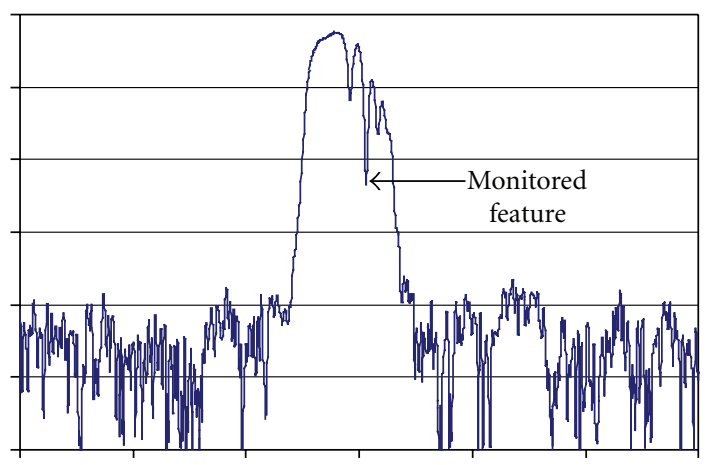

Figure 2: Spectrum of the etched core Fiber Bragg Grating sensor. The feature in the reflection spectrum that is being monitored is also shown.

$10.9 \mu \mathrm{m} / \mathrm{h}$. Etch rates vary with temperature and will vary by more than $2 \%$ per degree. In a first step, the diameter is reduced from $125 \mu \mathrm{m}$ to $49 \mu \mathrm{m}$. For this operation, the sensor is fully immersed within the etchant for 7 hours. In a second step, the lower grating is immersed in etchant and the upper half of the housing remains in air. The diameter is reduced from $49 \mu \mathrm{m}$ to the final etch diameter within 3.54.5 hours. Even though the etch rates are very uniform and reproducible, the final diameter of the sensor is achieved by monitoring the Bragg wavelength with an optical spectrum analyzer as the fiber is etched. A Bragg wavelength shift of $10.5 \mathrm{~nm}$ is measured when the fiber diameter is reduced from $125 \mu \mathrm{m}$ down to $5 \mu \mathrm{m}$. For a fiber diameter of $5 \mu \mathrm{m}$, none of the original fiber cladding is left and part of the core is etched away. For small diameters, the sensor becomes very sensitive to a change of the index of refraction of the surrounding liquid. Such enhanced sensitivity to a change of the index of refraction of the surrounding liquid was previously reported by our group [16]. BPM calculations were used to theoretically predict the Bragg shifts due to varying surrounding indices [18]. A sensitivity of about $85 \mathrm{~nm}$ for a change of 1 (riu) of the surrounding index of refraction was measured at a surrounding index of 1.4. As the surrounding index increases toward 1.45, a sensitivity of $1063 \mathrm{~nm} / \mathrm{riu}$ is expected. This sensitivity decreases to about $20 \mathrm{~nm} / \mathrm{riu}$ as the index of the surrounding liquid is changed to 1.3. In our studies, we take the index of refraction of water and ethanol at $1.55 \mu \mathrm{m}$ to be 1.319 and 1.356 , respectively. For an index of 1.44 , we have recently achieved an index change sensitivity of $9.4 \times 10^{-7}$ in a $3.4 \mu \mathrm{m}$ diameter sensor [17]. A YSI thermistor with $\Delta T=0.1^{\circ} \mathrm{C}$ (at room temperature) was immersed in solution near the grating at all times to accurately register the temperature.

For the reported experiments, we used a $5 \mu \mathrm{m}$ diameter etched fiber Bragg grating sensor. We use the broad band amplified spontaneous emission spectrum of an erbium doped fiber amplifier as the broad band source to probe the fiber Bragg reflection spectrum. A typical reflection spectrum of an etched core fiber Bragg grating is shown in Figure 2. As seen, there exist several reflectivity peaks and minima. We use one of the relative minima to monitor the wavelength shift. The feature is very reproducible and shifts 


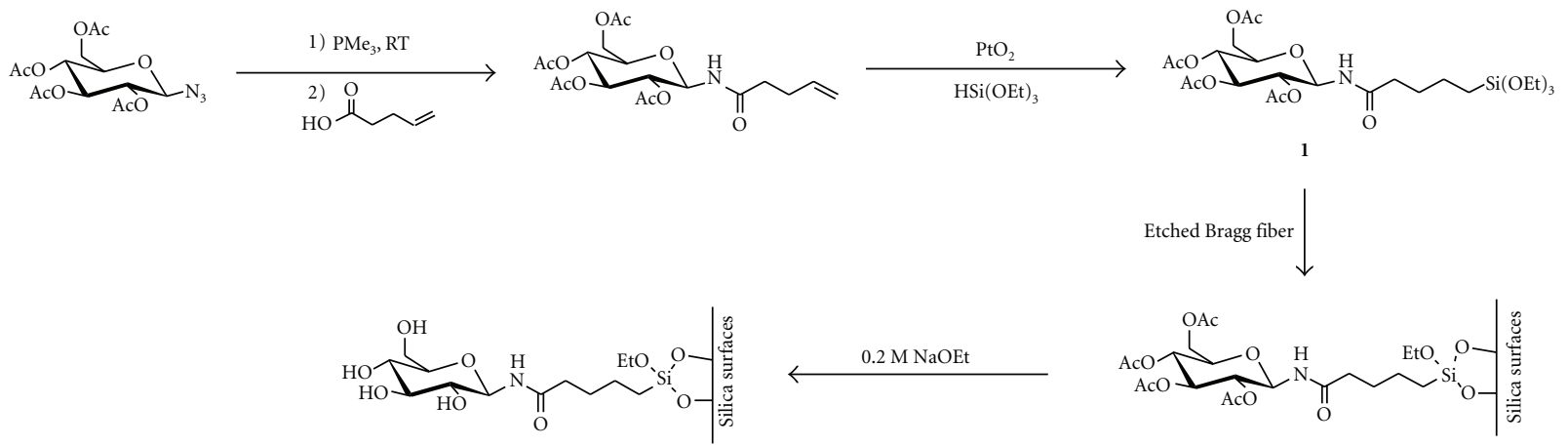

FIGURE 3: Synthesis of glucose-siloxane conjugate and surface functionalization.

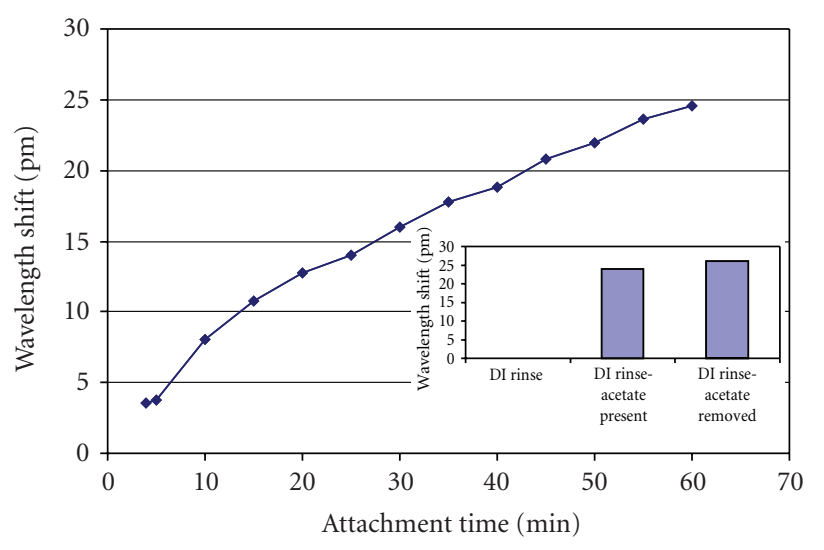

FIgURE 4: Time dependence of glucose-siloxane (1) attachment to the fiber Bragg grating in 95\% ethanol. Inset shows the observed wavelength shift after washing the fiber in water.

by the same amount as the peak wavelength. The $3 \mathrm{~dB}$ width of the minimum feature is $25 \mathrm{pm}$. By using an appropriate fitting function, the wavelength shift can be resolved down to $1 \mathrm{pm}$. This translates to a sensitivity of $1 \times 10^{-5}$ and $5 \times 10^{-5}$ in the index change for a surrounding index of 1.4 and 1.3, respectively.

\subsection{Synthesis of Glucosyl Siloxane and Functionalization of} the Etched Fiber Surface via Glucose Attachment. We have recently developed a general strategy for the synthesis of oligosaccharide conjugates that is the basis for attachment of carbohydrate derivatives to oxidized silica surfaces [19]. Although originally developed for the synthesis of complex glycopeptide derivatives, the methodology summarized in Figure 3 has proven to be viable for the synthesis of a wide variety of glycoconjugates such as glycolipids, glycosylated polyethylene glycol (PEG) derivatives, and glycosyl-siloxanes. For this paper, glucosylamide derivative 1 (Figure 3) was utilized to functionalize the surface of the etched fiber using sol-gel methodology (see Appendix A). Following attachment of $\mathbf{1}$ to the fiber, the acetate protecting groups were removed by treatment with sodium ethoxide in ethanol at room temperature (see Appendix A).
Although Figure 3 summarizes the method using glucose as the carbohydrate moiety, other monosaccharides (mannose and galactose), disaccharides (maltose, chitobiose, and lactose), trisaccharides (maltotriose and cellotriose), and polysaccharides (cellulose) derivatives have been prepared by this method. These results clearly demonstrate that virtually any polysaccharide cell surface component can be functionalized to a glass fiber using this methodology.

\section{Experimental Results}

Glucose modified fibers were prepared using the chemistry summarized in Figure 3. A freshly etched fiber was treated with a $10 \mathrm{mM}$ solution of glucose conjugate $\mathbf{1}$ dissolved in ethanol to yield a fiber whose surface has been modified by the siloxane exchange reaction and results in the attachment of the glucose ligand. Five different experiments were conducted with the identical goal of attaching glucosyl derivative 1 to the fiber via a covalent bond. These results were averaged and are plotted in Figure 4 . The error represented by the fluctuations from point to point is less than $2 \mathrm{pm}$. A growing shift of the Bragg wavelength is observed as attachment of the glucose-siloxane conjugate on the fiber progresses.

The attachment progresses more rapidly at the beginning and then slows down. At the end of the attachment experiment, the sensor was rinsed in ethanol and then rinsed in water. The inset in Figure 4 shows the shift of the fiber Bragg grating peak before and after glucose attachment measured with respect to water. A final shift of $24 \mathrm{pm}$ (as shown in the inset of Figure 4) is measured for the case of glucosyl derivative 1 , which corresponds to a change of the surrounding index of $5.6 \times 10^{-4}$. This shift is consistent with the $23 \mathrm{pm}$ time-dependent shift measure from the minima to the observed final value of the shift. If we assume that a solid glucose layer is formed on the fiber of index 1.543 [20], a beam propagation simulation previously discussed in [18] suggests that a layer of thickness about $1 \mathrm{~nm}$ is formed, which corresponds to a monolayer of glucose conjugate. When the acetate groups are removed using a $0.2 \mathrm{M}$ solution of sodium ethoxide, a glucose shift with respect to water of $26 \mathrm{pm}$ was registered. This shift is very similar to the shift that was measured for the acetylated glucose on the fiber, 


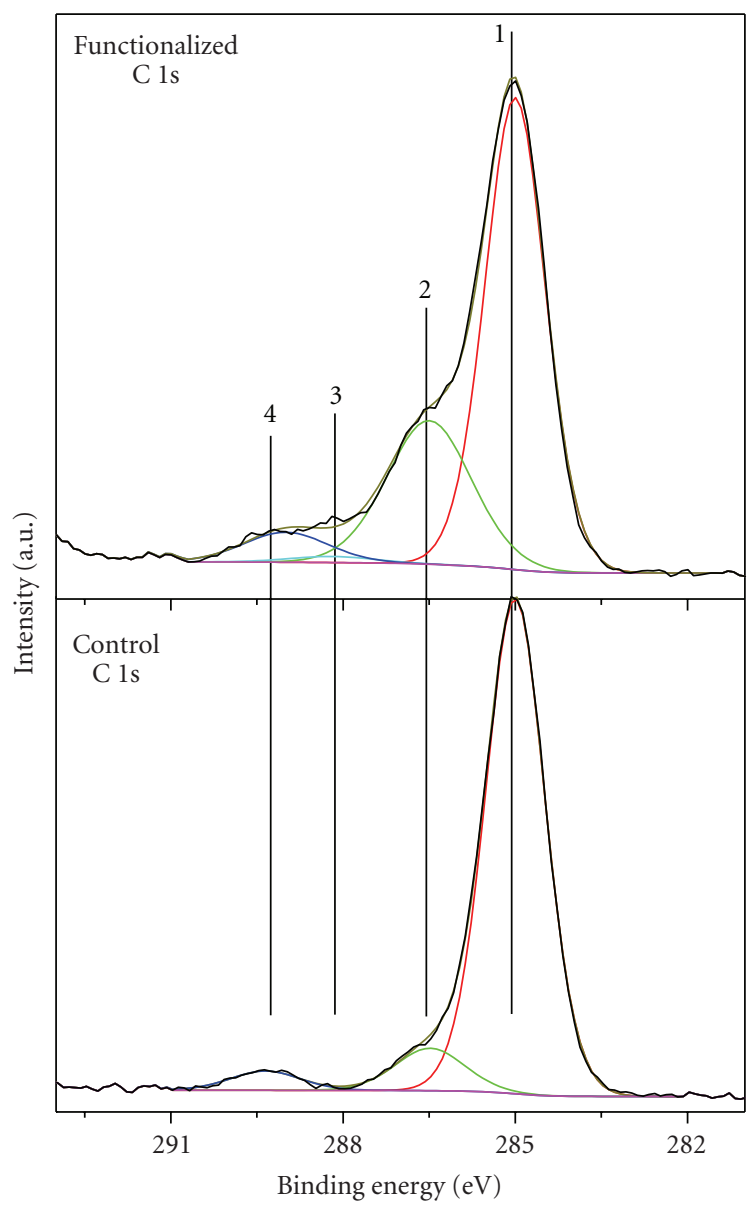

(a)

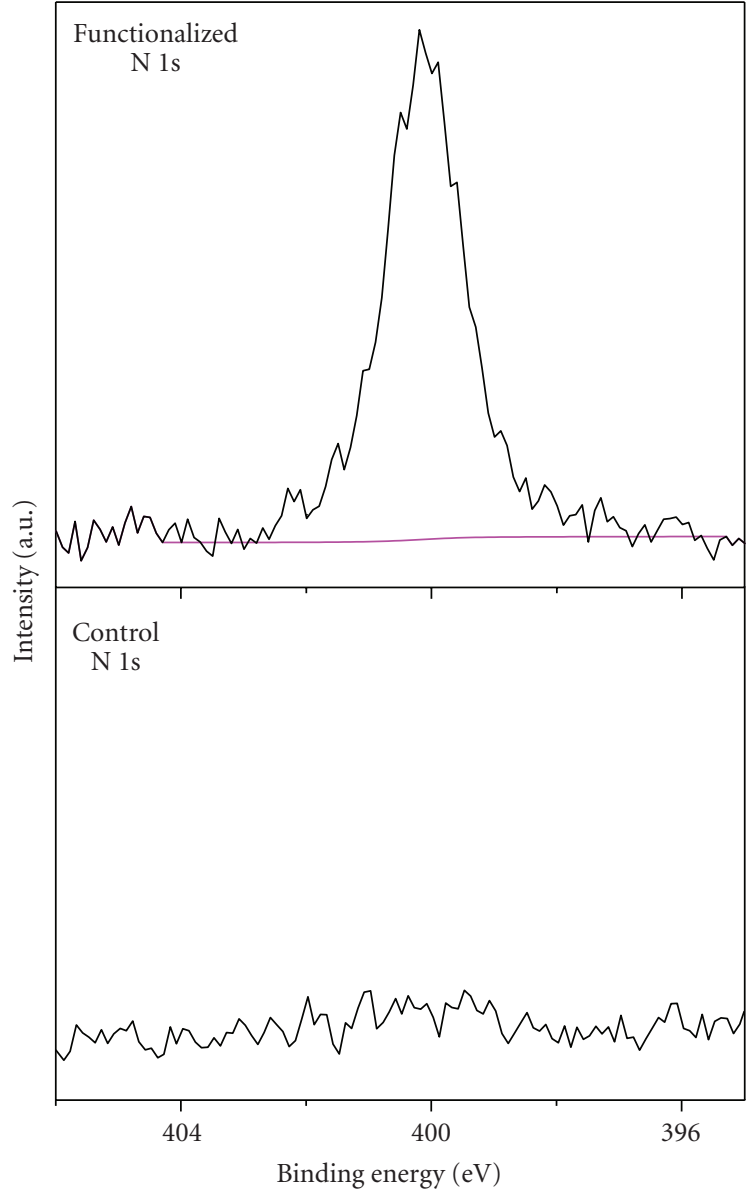

(b)

Figure 5: C 1s and $\mathrm{N}$ 1s high-resolution X-ray photoelectron spectra for the bare unfunctionalized glass slide (control) and glucosefunctionalized glass slide $(1=\mathrm{C}-\mathrm{C} / \underline{\mathrm{C}}-\mathrm{H}, 2=\underline{\mathrm{C}}-\mathrm{O} / \underline{\mathrm{C}}-\mathrm{N}, 3=\mathrm{R} \underline{\mathrm{C}}=\mathrm{ON}, 4=\mathrm{O} \underline{\mathrm{C}}=\mathrm{OR})$.

indicating that only a small fraction of the acetate groups has been removed. We have previously reported on the time dependence of the attachment of APTES and APMDS on a fiber [21] and have demonstrated the power of our technique for being able to reach monolayer attachment in a controlled way, as compared to other techniques that do not allow in situ real-time measurement of the functionalization process [22]. Therefore, we conclude that approximately a monolayer of the glucose-siloxane conjugate was attached to the fiber under these conditions.

Attempts to characterize glucose-siloxane 1 attachment to the fiber's surface using X-ray photoelectron spectroscopy (XPS) were inconclusive due to the weak signal obtained from the functionalized fiber. In an effort to demonstrate that glucose-siloxane 1 can be immobilized onto a silica surface, an etched glass slide was functionalized with glucosesiloxane 1 (see Appendix B) and then analyzed by XPS. The larger surface area of the slide provided an increased signal in the XPS spectrum. The high-resolution X-ray photoelectron spectra for bare and functionalized glass slides are depicted in Figure 5 (see Appendix B for experimental details and instrument specifications). The C 1s spectrum of the unfunctionalized glass slide (following the cleaning and etching procedures and washing with water) indicates a small amount of carbon on the surface due to hydrocarbon contamination, with some oxidized carbon due to atmospheric exposure. Notably, there is no nitrogen detected on the surface of the bare unfunctionalized glass slide. However, the XPS spectrum of the glass slide that was treated with glucose-siloxane 1 reveals a well-resolved nitrogen peak at $400.2 \mathrm{eV}(\sim 2$ atomic \% of all elements detected) and increased oxidized carbon species $(\mathrm{C}=\mathrm{O}, \mathrm{C}-\mathrm{N}$, and $\mathrm{C}-\mathrm{O})$, which is consistent with the attachment of the protected glucose-siloxane conjugate.

Additional confirmation of the functionalization of the fiber's surface with glucose was demonstrated using a lectin binding assay. Exposure of the glucose-functionalized fiber to a solution of concanavalin A (Con A), a protein known to bind to glucose, at $23^{\circ} \mathrm{C}$ resulted in a shift of $21 \mathrm{pm}$ in the signal and indicated that binding of Con A had occurred to the fiber (Figure 6). Analogous treatment of the glucose-functionalized fiber with peanut agglutinin, a carbohydrate binding protein that binds to galactose 


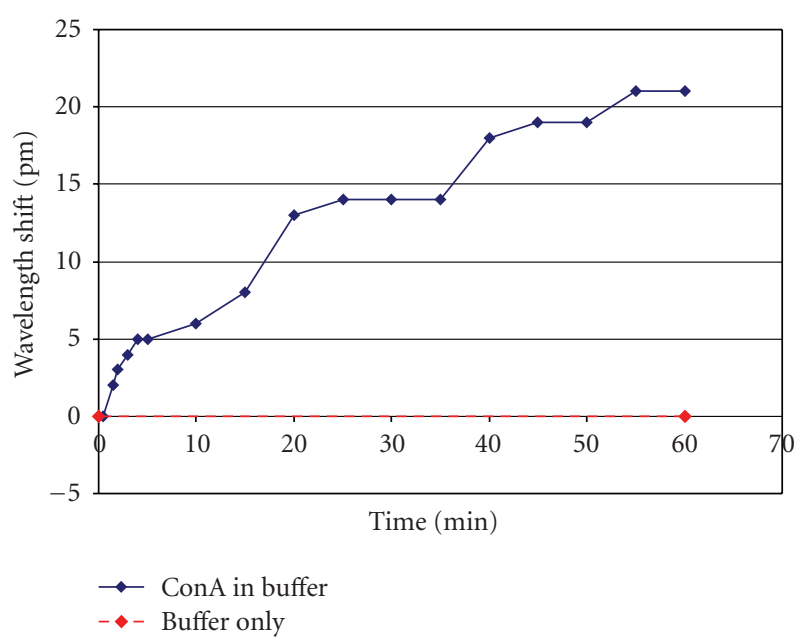

Figure 6: Time dependence of binding of Con A to glucosefunctionalized fiber Bragg sensor at $23^{\circ} \mathrm{C}$ in buffer.

rather than glucose, did not produce a change in the signal of the fiber $(\Delta=0 \mathrm{pm})$. These complementary binding studies employing known lectins, although preliminary, were important on two levels: first, the binding clearly indicated that the surface of the fiber had been functionalized with glucose-siloxane $\mathbf{1}$ and that treatment with ethoxide had resulted in removal of the acetate protecting groups. More importantly, the binding of well-characterized lectins, carbohydrate-binding proteins, can be determined using the resulting sensor. Accordingly, we anticipate that other lectins whose specificity is unknown can be determined employing analogous methodology with more complex carbohydrate derivatives.

\section{Conclusion}

An evanescent wave fiber Bragg grating sensor has been prepared and was used to monitor the covalent attachment of a glucose derivative to the surface of the fiber. The observed change in the index was consistent with deposition of approximately a monolayer of the glucose conjugate. After removal of the carbohydrate protecting groups, the lectin concanavalin A was shown to bind to the biosensor. Such probes that rely on cell surface binding events as the basis of the sensing would have distinct advantages over other sensing strategies because (1) the sensors would not require lysis of cells prior to measuring binding and (2) the binding events should occur rapidly, possibly in real time. Subsequent experiments with this and related carbohydrate-functionalized Bragg fiber gratings will be undertaken to demonstrate the scope and limitations of these carbohydrate-functionalized biosensors. Topics to be investigated include temperature and $\mathrm{pH}$ stability of the biosensors, specificity of lectin binding to various carbohydrates, the role of tether length on the binding specificity, and the ability to multiplex biosensors to create devices for the detection of important proteins via carbohydrate-protein interactions.

\section{Appendices}

\section{A. Preparation of Glucose-Functionalized Fiber}

A.1. Synthetic Procedure for Acetylated- $\beta$-Glucose-4-Pentenamide. Acetylated glucose-azide was prepared as described in [19]. Acetylated- $\beta$-glucose-4-pentenamide was prepared in the following manner: Acetylated glucose-azide $(1.0 \mathrm{~g}$, $2.7 \mathrm{mmol}$ ) was dissolved in $25 \mathrm{~mL}$ of freshly distilled $\mathrm{CH}_{2} \mathrm{Cl}_{2}$. Diisopropylethylamine $(1.0 \mathrm{~mL})$ was added via syringe followed by a $1.0 \mathrm{M}$ solution of trimethylphosphine $(3.5 \mathrm{~mL}$, $3.5 \mathrm{mmol}$ ) via syringe. Evolution of gas was observed. The reaction mixture stirred at RT for 0.5 hours. 4-Pentenoic acid $(0.6 \mathrm{~mL}, 5.4 \mathrm{mmol})$ was added via syringe. The reaction mixture stirred at RT for 22 hours. The reaction mixture was then diluted with $125 \mathrm{~mL}$ of EtOAc and washed three times with $\mathrm{H}_{2} \mathrm{O}$. The organic layer was collected, dried over $\mathrm{MgSO}_{4}$ and concentrated in vacuo to yield a colorless oil. Purification of the oil by flash chromatography (hexanes: EtOAc, $1: 1)$ gave $0.62 \mathrm{~g}(54 \%)$ of acetylated $\beta$-glucose-4pentenamide as a colorless oil. IR $\left(\mathrm{CCl}_{4}, \mathrm{~cm}^{-1}\right) 3432(\mathrm{w})$, 3080 (w), 2955 (w), 1759 (s), 1709 (s), 1509 (s), 1227 (s), $909(\mathrm{~m}) ;{ }^{1} \mathrm{H} \mathrm{NMR}\left(400 \mathrm{MHz}, \mathrm{CDCl}_{3}\right) \delta 1.99(\mathrm{~s}, 3 \mathrm{H}), 2.00(\mathrm{~s}$, $3 \mathrm{H}), 2.02(\mathrm{~s}, 3 \mathrm{H}), 2.05(\mathrm{~s}, 3 \mathrm{H}), 2.18-2.36(\mathrm{~m}, 4 \mathrm{H}), 3.79$ (ddd, $\mathrm{J}=9.5,4.4,2.2,1 \mathrm{H}), 4.05(\mathrm{dd}, \mathrm{J}=12.4,2.2,1 \mathrm{H}), 4.28(\mathrm{dd}, \mathrm{J}$ $=12.4,4.4,1 \mathrm{H}), 4.86(\mathrm{t}, \mathrm{J}=9.5,1 \mathrm{H}), 4.98(\mathrm{dd}, \mathrm{J}=10.3,1.6$, $1 \mathrm{H}), 5.02(\mathrm{dd}, \mathrm{J}=17.3,1.6,1 \mathrm{H}), 5.03(\mathrm{t}, \mathrm{J}=9.5,1 \mathrm{H}), 5.23$ $(\mathrm{t}, \mathrm{J}=9.5,1 \mathrm{H}), 5.28(\mathrm{t}=9.5,1 \mathrm{H}), 5.70-5.80(\mathrm{~m}, 1 \mathrm{H}), 6.20$ $(\mathrm{d}, \mathrm{J}=9.5,1 \mathrm{H}) ;{ }^{13} \mathrm{C}$ NMR $\left(100 \mathrm{MHz}, \mathrm{CDCl}_{3}\right) \delta 20.6,20.6$, 20.7, 20.7, 28.8, 35.6, 61.6, 68.1, 70.5, 72.6, 73.5, 78.1, 115.8, $136.3,169.5,169.8,170.6,171.0,172.5$; HRMS (FAB) cacld. for $\mathrm{C}_{19} \mathrm{H}_{28} \mathrm{O}_{10} \mathrm{~N}[\mathrm{M}+\mathrm{H}]^{+} 430.1713$, found 430.1708 .

A.2. Synthetic Procedure for Acetylated $\beta$-Glucose-5-(Triethoxysilyl)pentanamide 1 . Acetylated $\beta$-glucose-4-pentenamide $(0.43 \mathrm{~g}, 1.0 \mathrm{mmol})$ and $\mathrm{PtO}_{2}(0.01 \mathrm{~g}, 0.05 \mathrm{mmol})$ were weighed into a vial and dissolved with $1.5 \mathrm{~mL}$ of freshly distilled THF. Triethoxysilane $(0.9 \mathrm{~mL}, 5 \mathrm{mmol})$ was added via syringe in one portion. The vial was flushed with argon and sealed. The reaction mixture stirred at $95^{\circ} \mathrm{C}$ for 3 hours. The reaction mixture was diluted with $20 \mathrm{~mL}$ of $\mathrm{EtOH}$ and filtered through a Celite plug. Concentration in vacuo yielded a colorless oil. Purification by flash chromatography (hexanes: EtOAc, $1: 1$ ) gave $0.42 \mathrm{~g}$ of an inseparable mixture of Acetylated $\beta$-glucose-5-(triethoxysilyl)pentanamide $\mathbf{1}$ and the fully hydrogenated amide product. The mol ratio of $\mathbf{1}$ : hydrogenated product $(3: 1)$ and percent yields (57\% for 1 and $18 \%$ for the hydrogenated product) were determined by integration of the ${ }^{1} \mathrm{H}-\mathrm{NMR}$ signals at $0.60 \mathrm{ppm}$ (corresponding to the protons on the carbon adjacent to the siloxane group in 1) and $0.88 \mathrm{ppm}$ (corresponding to the protons on the terminal carbon in the hydrogenated product). IR $\left(\mathrm{CCl}_{4}\right.$, $\left.\mathrm{cm}^{-1}\right) 3432(\mathrm{w}), 2973(\mathrm{~m}), 1755(\mathrm{~s}), 1707(\mathrm{~m}), 1511(\mathrm{~m})$, $1224(\mathrm{~s}), 956(\mathrm{w}){ }^{1} \mathrm{H}$ NMR $\left(1,400 \mathrm{MHz}, \mathrm{CDCl}_{3}\right) \delta 0.57-$ $0.62(\mathrm{~m}, 2 \mathrm{H}), 1.19(\mathrm{t}, \mathrm{J}=7.0,9 \mathrm{H}), 1.35-1.42(\mathrm{~m}, 2 \mathrm{H}), 1.57-$ $1.63(\mathrm{~m}, 2 \mathrm{H}), 1.99(\mathrm{~s}, 3 \mathrm{H}), 2.00(\mathrm{~s}, 3 \mathrm{H}), 2.02(\mathrm{~s}, 3 \mathrm{H}), 2.05$ $(\mathrm{s}, 3 \mathrm{H}), 2.14-2.20(\mathrm{~m}, 2 \mathrm{H}), 3.77(\mathrm{q}, \mathrm{J}=7.0,6 \mathrm{H}), 3.78-3.82$ $(\mathrm{m}, 1 \mathrm{H}), 4.04(\mathrm{dd}, \mathrm{J}=12.4,2.0,1 \mathrm{H}), 4.28(\mathrm{dd}, \mathrm{J}=12.4$, $4.4,1 \mathrm{H}), 4.88(\mathrm{t}, \mathrm{J}=9.5,1 \mathrm{H}), 5.04(\mathrm{t}, \mathrm{J}=9.5,1 \mathrm{H}), 5.22$ 
$(\mathrm{t}, \mathrm{J}=9.5,1 \mathrm{H}), 5.28(\mathrm{t}, \mathrm{J}=9.5,1 \mathrm{H}), 6.16(\mathrm{~d}, \mathrm{~J}=9.5,1 \mathrm{H})$; ${ }^{13} \mathrm{C} \mathrm{NMR}\left(1,100 \mathrm{MHz}, \mathrm{CDCl}_{3}\right) \delta 10.2,18.3$ (x 3), 20.6, 20.6, 20.6, 20.7, 22.5, 28.4, 36.3, 58.3 (x 3), 61.6, 68.1, 70.5, 72.6, $73.5,78.1,169.5,169.8,170.6,171.1,173.2 ;{ }^{29} \mathrm{Si}$ NMR (1, $79.5 \mathrm{MHz} \mathrm{CDCl}_{3}$, externally referenced to TMS at $0 \mathrm{ppm}$ ) $\delta^{-}$45.6; HRMS (FAB) cacld. for $\mathrm{C}_{25} \mathrm{H}_{43} \mathrm{O}_{13} \mathrm{NSiLi}[\mathrm{M}+\mathrm{Li}]^{+}$ 600.2664 , found 600.2694

A.3. Procedure for the Deprotection of Acetylated GlucoseSiloxane Conjugate Immobilized onto a Bragg Fiber. A Bragg fiber functionalized with glucose-siloxane conjugate $\mathbf{1}$ was immersed in a $0.2 \mathrm{M} \mathrm{NaOEt} / \mathrm{EtOH}$ solution for 2.0 hours at $25^{\circ} \mathrm{C}$. The fiber was then removed from the sodium-ethoxide solution and rinsed with ethanol followed by Millipore water.

\section{B. Preparation of Glucose-Functionalized Glass Surface and XPS Data}

B.1. Procedure for the Immobilization of Glucose-Siloxane 1 onto an Etched Glass Slide. A glass cover slip (Fisherbrand Microscope Cover Glass) was immersed in piranha solution ( 3 : 1 concentrated $\mathrm{H}_{2} \mathrm{SO}_{4}: 30 \% \mathrm{H}_{2} \mathrm{O}_{2}$ ) for 1 hour, rinsed with Millipore $\mathrm{H}_{2} \mathrm{O}(50 \mathrm{~mL})$, and then immersed in $7: 1$ buffered oxide etch with surfactant from J. T. Baker for 1 hour. The slide was then rinsed with Millipore $\mathrm{H}_{2} \mathrm{O}$ followed by sonication in Millipore $\mathrm{H}_{2} \mathrm{O}$ for 10 minutes. The sonication process was repeated with fresh Millipore $\mathrm{H}_{2} \mathrm{O}$. The slide was then rinsed with dichloromethane $(50 \mathrm{~mL})$ and dried in an oven at $200^{\circ} \mathrm{C}$ for 1.5 hours. After cooling in a desiccator, a solution of glucose-siloxane $\mathbf{1}$ dissolved in dichloromethane was added drop wise to one side of the glass slide. After sitting undisturbed under nitrogen atmosphere for 0.5 hour, the glucose-siloxane/dichloromethane solution was reapplied. The glass slide sat undisturbed under nitrogen atmosphere for an additional 0.5 hour. The glass slide was rinsed with dichloromethane $(20 \mathrm{~mL})$ and was allowed to sit undisturbed under nitrogen atmosphere overnight.

B.2. Experimental Details for the XPS Analysis of Bare and Glucose-Functionalized Glass Slides. The XPS data was collected on a Kratos Axis 165 X-ray photoelectron spectrometer operating in hybrid mode using monochromatic $\mathrm{Al} \mathrm{K} \alpha$ radiation. The instrument maintained a pressure of $5 \times 10^{-9}$ Torr or better during data collection. The data were collected at a $20^{\circ}$ take-off-angle (with respect to the sample plane). Charge neutralization was required to compensate for sample charging. Survey spectra (not shown here) were collected at a pass energy of $160 \mathrm{eV}$, while high resolution spectra were collected at a pass energy of $20 \mathrm{eV}$. All spectra were calibrated to the hydrocarbon peak at $285 \mathrm{eV}$. The C 1s spectra were fit with a Shirley background and peaks of a 30\% Lorentzian 70\% Gaussian product function.

\section{Acknowledgments}

PD acknowledges the generous financial support of the National Science Foundation (NIRT, CHE 0511219478), the Maryland Technology Development Corporation and SD
Nanosciences, Inc. for partial support of this study. We gratefully acknowledge shared experimental facilities support for the X-ray Photoelectron Spectrometer from the NSF MRSEC under Grant DMR 05-20471. MTH acknowledges the support of the Graduate Assistance in Areas of the National Need (GAANN) Fellowship.

\section{References}

[1] M. Valach and E. Sturdik, "Application of biosensors in monitoring fermentation processes," Chemicke Listy, vol. 103, no. 3, pp. 208-215, 2009.

[2] L. C. Shriver-Lake, P. T. Charles, and C. R. Taitt, "Immobilization of biomolecules onto silica and silicabased surfaces for use in planar array biosensors," in Biosensors and Biodetection, Vol. 2, vol. 504 of Methods in Molecular Biology, pp. 419-440, 2009.

[3] A. Rasooly and K. E. Herold, Biosensors and Biodetection: Methods and Protocols Volume 2: Electrochemical and Mechanical Detectors, Lateral Flow and Ligands for Biosensors, Humana Press, Totowa, NJ, USA, 2009.

[4] L. Mi, X. Zhang, W. Yang, et al., "Artificial nano-biocomplexes: effects of nanomaterials on biomolecular reactions and applications in biosensing and detection," Journal of Nanoscience and Nanotechnology, vol. 9, no. 4, pp. 2247-2255, 2009.

[5] F. Lu, L. Gu, M. J. Meziani, et al., "Advances in bioapplications of carbon nanotubes," Advanced Materials, vol. 21, no. 2, pp. 139-152, 2009.

[6] G. R. Hendrickson and L. A. Lyon, "Bioresponsive hydrogels for sensing applications," Soft Matter, vol. 5, no. 1, pp. 29-35, 2009.

[7] G. Blagoi, N. Rosenzweig, and Z. Rosenzweig, "Fluorescence resonance energy transfer-based sensors for bioanalysis," Fluorescence Sensors and Biosensors, pp. 93-105, 2006.

[8] L. De Hoff Peter, M. Brill Laurence, and M. Hirsch Ann, "Plant lectins: the ties that bind in root symbiosis and plant defense," Molecular Genetics and Genomics, vol. 282, no. 1, pp. 1-15, 2009.

[9] S. Nakahara and A. Raz, "Biological modulation by lectins and their ligands in tumor progression and metastasis," AntiCancer Agents in Medicinal Chemistry, vol. 8, no. 1, pp. 22-36, 2008.

[10] V. Martos, P. Castreño, J. Valero, and J. de Mendoza, "Binding to protein surfaces by supramolecular multivalent scaffolds," Current Opinion in Chemical Biology, vol. 12, no. 6, pp. 698706, 2008.

[11] T. Horlacher and P. H. Seeberger, "Carbohydrate arrays as tools for research and diagnostics," Chemical Society Reviews, vol. 37, no. 7, pp. 1414-1422, 2008.

[12] S. Chen and B. B. Haab, "Antibody microarrays for protein and glycan detection," Clinical Proteomics, pp. 101-111, 2008.

[13] M. Izumi and H. Uzawa, "Carbohydrate-based sensing materials for detection of bacterial toxins," Trends in Glycoscience and Glycotechnology, vol. 17, no. 95, pp. 107-119, 2005.

[14] R. Jelinek and S. Kolusheva, "Carbohydrate biosensors," Chemical Reviews, vol. 104, no. 2, pp. 5987-6015, 2004.

[15] C. R. Taitt, L. C. Shriver-Lake, M. M. Ngundi, and F. S. Ligler, "Array biosensor for toxin detection: continued advances," Sensors, vol. 8, no. 12, pp. 8361-8377, 2008.

[16] A. N. Chryssis, S. M. Lee, S. B. Lee, S. S. Saini, and M. Dagenais, "High sensitivity evanescent field fiber bragg grating sensor," IEEE Photonics Technology Letters, vol. 17, no. 6, pp. 1253-1255, 2005. 
[17] M. Dagenais and C. J. Stanford, "Evanescent fiber bragg grating bio-sensors," in VLSI Micro- and Nanophotonics: Science, Technology, and Applications, E.-H. Lee, L. Eldada, M. Razeghi, and C. Jagadish, Eds., Taylor and Francis, London, UK, 2009.

[18] S. S. Saini, C. Stanford, S. M. Lee, et al., "Monolayer detection of biochemical agents using etched-core fiber bragg grating sensors," IEEE Photonics Technology Letters, vol. 19, no. 18, pp. 1341-1343, 2007.

[19] F. Damkaci and P. DeShong, "Stereoselective synthesis of aand b-glycosylamide derivatives from glycopyranosyl azides via Isoxazoline intermediates," The Journal of the American Chemical Society, vol. 125, no. 15, pp. 4408-4409, 2003.

[20] X. Cao, B. C. Hancock, N. Leyva, J. Becker, W. Yu, and V. M. Masterson, "Estimating the refractive index of pharmaceutical solids using predictive methods," International Journal of Pharmaceutics, vol. 368, pp. 16-23, 2009.

[21] C. J. Stanford, M. Dagenais, J.-H. Park, and P. DeShong, "Real-time monitoring of siloxane monolayer film formation on silica using a fiber bragg grating," Current Analytical Chemistry, vol. 4, no. 4, pp. 356-361, 2008.

[22] J. A. Howarter and J. P. Youngblood, "Optimization of silica silanization by 3-aminopropyltriethoxysilane," Langmuir, vol. 22, no. 26, pp. 11142-11147, 2006. 

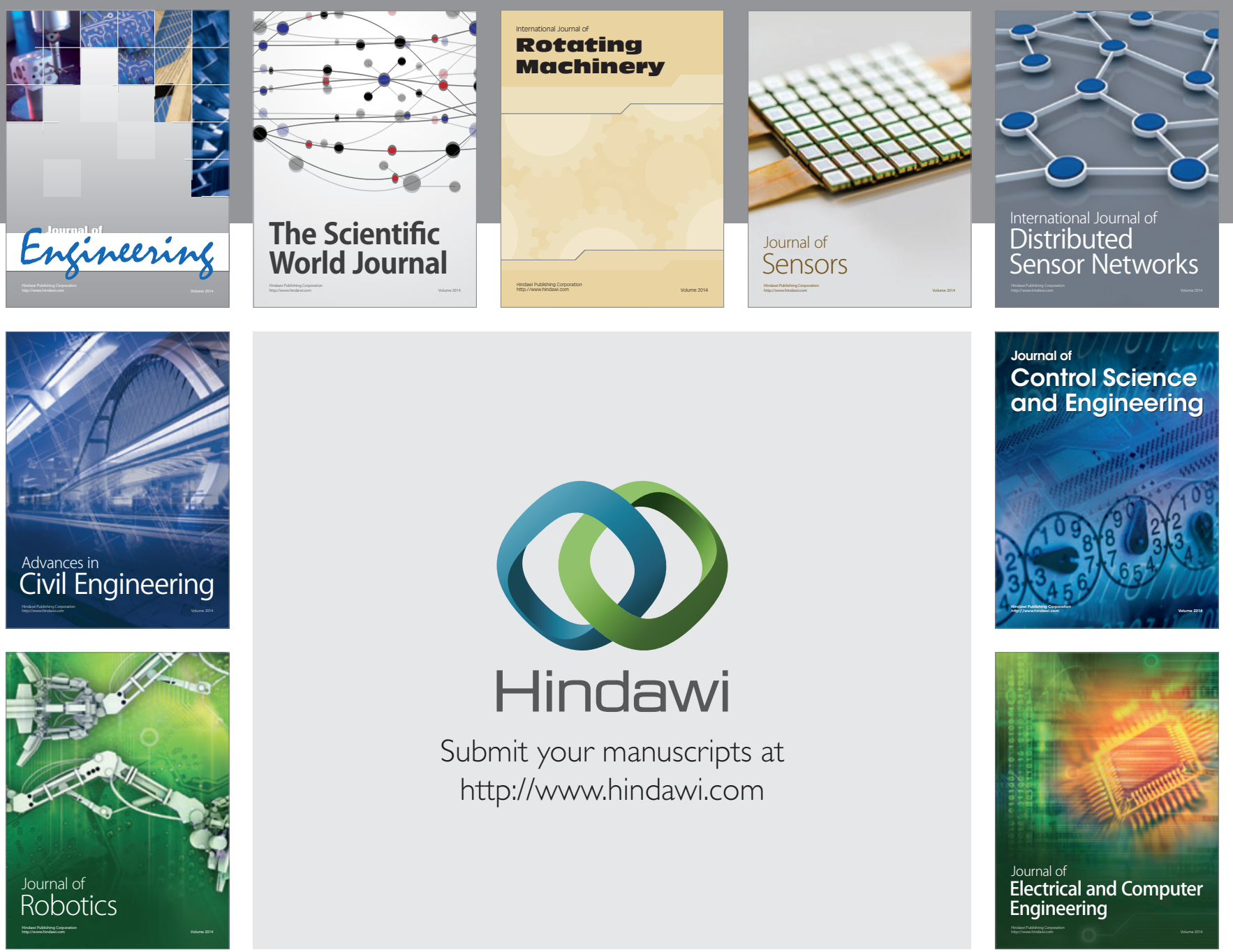

Submit your manuscripts at

http://www.hindawi.com
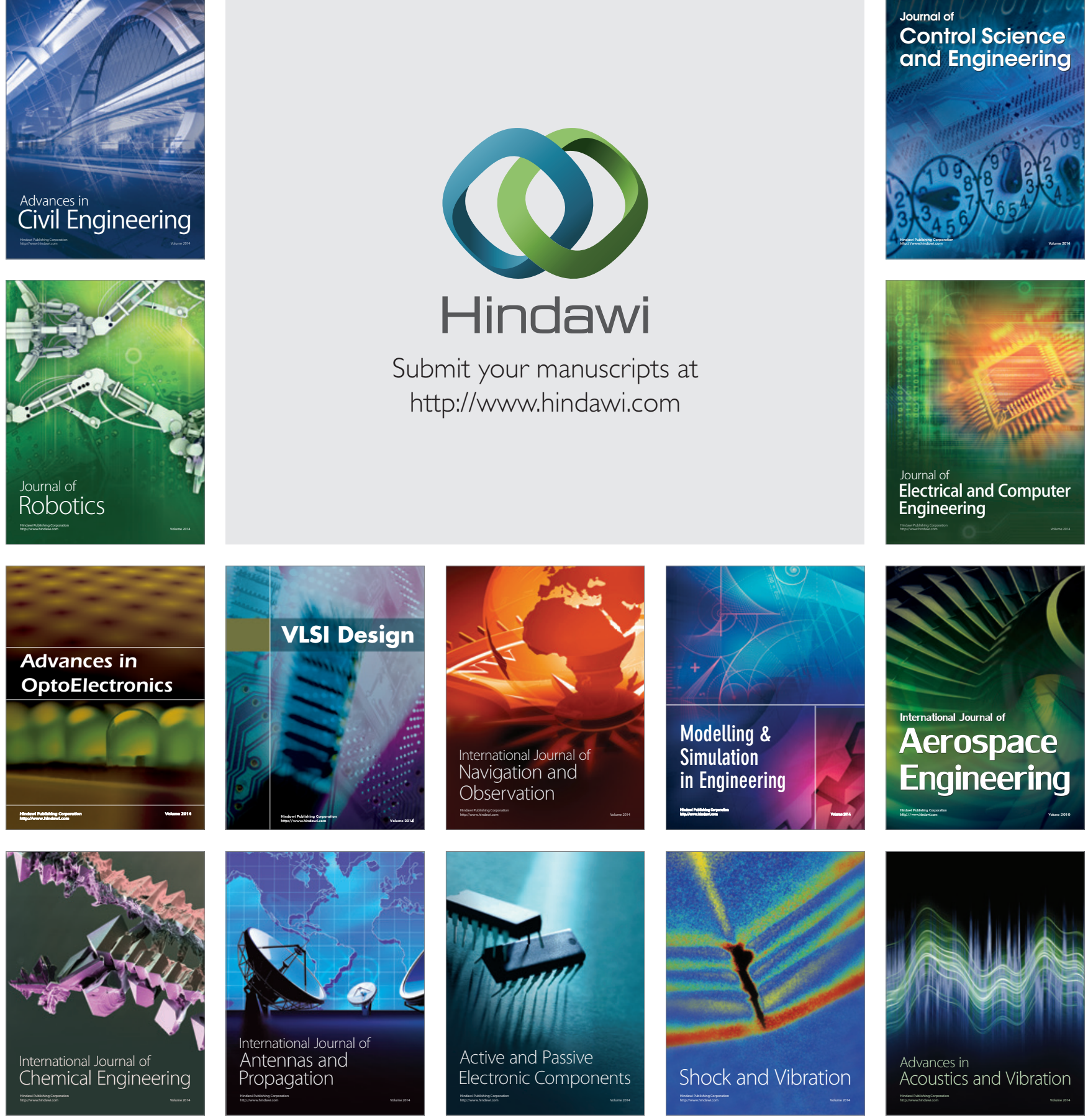